\title{
O FORDISMO ACADÊMICO NA EDUCAÇÃO FÍSICA
}

\author{
GRAD. EDUARDO RUMENIG SOUZA
}

Mestrando em Educação Física pela Escola de Educação Física e Esporte da Universidade de São Paulo e Professor da Rede Pública Municipal de Ensino de São Paulo (São Paulo - Brasil) e-mail: erumenig@hotmail.com

\section{GRAD. ALEXANDRE LUZZI}

Bacharelado e Licenciado em Educação Física pela FMU e Professor do Colégio Marista Arquidiocesano de São Paulo (São Paulo - Brasil) e-mail: alexluzzi@hotmail.com

\section{DR. BENEDITO PEREIRA}

Doutor em Biologia Funcional e Molecular pela UNICAMP e Professor Doutor da Escola de Educação Física e Esporte da Universidade de São Paulo (São Paulo - Brasil)

e-mail: benepe@usp.br

\section{RESUMO}

Apesar da consolidação dos programas de pós-graduação stricto sensu em Educação Física (PPG-EF), críticas têm sido evidenciadas. Dentre as principais destacam-se a formação técnica e a especialização nos períodos iniciais de formação científica, a distância entre conhecimento produzido e sociedade e a valorização quantitativa da produção bibliográfica, orientando os objetivos da pesquisa para a publicação. Denominamos esse modo de produção científica de fordismo acadêmico. Assim, o objetivo do ensaio é discutir a orientação política dos PPG-EF e problematizar suas implicações para produção do conhecimento e a formação acadêmica. A ênfase na produção bibliográfica e a desvalorização da EF enquanto área de intervenção pode comprometer a formação crítica e resultar em descaracterização da área.

PALAVRAS-CHAVE: Pós-graduação; política científica; produção do conhecimento. 
Apesar da consolidação da pós-graduação stricto sensu em Educação Física (PPG-EF) na última década, críticas em relação à política que orienta esses programas, sobremodo a produção e avaliação do conhecimento têm sido foco de discussões há anos (PEREIRA, 1998; KOKUBUN, 2003; BETTI et al., 2004; LOVISIOLO, 2005; TAFFAREL, 2007; TANI, 2007).

Sobre a produção do conhecimento, Machado, Lourenço e Silva (2000) salientam que o exercício da reflexão, realizado por meio das pesquisas teórica e conceitual, é condição sine qua nom para a compreensão e desenvolvimento efetivo da área acadêmica. Todavia, em diversas áreas do conhecimento usualmente observa-se uma tendência a enaltecer a pesquisa factual, desqualificando outras formas de investigação (PARDO; RIGO, 2000).

Os PPG-EF também parecem estar alinhados com essa política da quantidade, visto que houve um crescimento quantitativo de diversas subdisciplinas e uma valorização da especialização e da aprendizagem técnica (principalmente nos períodos iniciais da carreira científica), mas que não foi acompanhado, proporcionalmente, por um desenvolvimento qualitativo da área. Essa política dos PPG-EF pode distanciar o conhecimento da vida social e comprometer a formação de mestres e doutores plenos de sua função'.

Por desenvolvimento qualitativo da área podemos compreender a formação de pesquisadores críticos, politizados e qualificados para buscar soluções aos graves problemas da humanidade, alinhando a produção cientifica e epistemológica da EF com uma "ética da vida" (o conceito de "ética da vida" remete a FREIRE, 1996).

No intuito de diminuir a distância existente entre a universidade e a vida social, alguns autores (CARDOSO et al., 2009) defenderam PPG orientados ao setor produtivo, sob a justificativa de que promoveriam o desenvolvimento tecnológico do país e garantiriam a transferência do conhecimento à sociedade. $\bigcirc$ mestrado profissional seria a consolidação de tais propostas, atendendo às exigências do setor produtivo, tornando a formação superior mais dinâmica e preparando os pós-graduandos para outras carreiras além da universitária. Todavia, o mestrado profissional parece deturpar a proposta inicial dos PPG stricto sensu, que em síntese consiste na formação para docência e pesquisa.

Associado à valorização da especialização técnica e da pesquisa factual está a avaliação desses programas, baseada em indicadores que favorecem a política da produção de informação sem necessariamente revertê-la em avanços concretos

I. Mestres e doutores plenos são aqueles capazes de selecionar, organizar, sintetizar, produzir e difundir conhecimento. 
para a área e sociedade, tornando o trabalho científico um fim em si mesmo. Talvez alguns fatores históricos tenham contribuído para a solidificação do sistema que vivenciamos hoje.

Primeiro é inerente à própria Educação Física e faz juízo ao movimento originado em 1960, conhecido como "Movimento Disciplinar da Educação Física"; dirigido basicamente pelos professores Henry (1964) e Rarick (1967). Nesse período, houve uma necessidade de produção científica para justificar a EF como disciplina acadêmica; mesmo que essa produção fosse orientada aos interesses de outros campos do saber, denominados "ciências-mãe" (TANI, 1999). A EF seguiu esse modelo americano de ciência, alicerçado pelo projeto político de desenvolvimento do país na década de 1970, estabelecendo uma certa dependência tecnológica e humana (SIIVA, 1998).

O segundo seria a constituição da universidade dentro do modelo capitalista, que fomenta uma produção científica e cultural competitiva e orientada a certos interesses de uma elite econômica (RIBEIRO, 1975). Nesse contexto, a informação torna-se um produto que possui um valor e contribui para sustentar uma ideologia científica descomprometida com os interesses da área e do país. Sob uma aparente neutralidade, o discurso ideológico científico produzido a partir de interesses econômicos cria no meio acadêmico a rivalidade entre departamentos e o descomprometimento político dos docentes e estudantes.

Considerando que a EF constitui-se como área de intervenção, o desenvolvimento de iniciativas que favoreçam uma maior relação entre disciplina acadêmica e profissão é fundamental (BRESSAN, 1979). É importante salientar que isso não implica em abandonar as questões acadêmicas, mas em abordar os problemas profissionais de forma acadêmica (BETTI et al., 2004).

O equilíbrio epistêmico entre pesquisa factual, conceitual e teórica e a orientação política dos PPG, aproximando academia e sociedade são questões pertinentes que têm sido pouco discutidas no âmbito acadêmico. Apesar da necessidade de problematizar todas essas questões, o presente estudo se restringirá a discutir a orientação política dos PPG-EF e problematizar suas implicações para produção do conhecimento e formação acadêmica em EF.

\section{CARACTERIZAÇÃO DOS PROGRAMAS DE PÓS-GRADUAÇÃO EM EDUCAÇÃO FÍSICA}

O desenvolvimento da pós-graduação no Brasil é recente e data de 1970. Foi nesse período que a ciência e a tecnologia passaram a ser consideradas pelo governo como elemento estratégico para o desenvolvimento socioeconômico do 
país (SILVA, 1998). O governo militar elaborou uma série de proposições políticas sob a égide do Programa Estratégico de Desenvolvimento (PED - 1968 / 1970), que entre outras medidas promoveu a criação e diversificação das agências de fomento à pesquisa, além da institucionalização e regulamentação de espaços para a produção científica e tecnológica.

A Educação Física também foi favorecida com essa política de desenvolvimento, pois o esporte seria utilizado como publicidade para divulgar ao mundo nosso desenvolvimento nacional. Além disso, havia o interesse em promover programas de pós-graduação em Educação Física para que essa área acompanhasse o desenvolvimento geral do país em outras áreas do conhecimento (SILVA, 2005). Assim, em 1975 foi criado o Grupo de Consultoria Externa (GCE) do Departamento de Educação Física e Desporto / Ministério da Educação (MEC), instituído pela portaria $\mathrm{n}$. 168/75 e, dois anos mais tarde, surge na Universidade de São Paulo o primeiro mestrado em Educação Física do Brasil e da América Latina (SILVA, 2005).

O último balanço da CAPES (Coordenação de Aperfeiçoamento de Pessoal de Nível Superior) realizado em 2006 apontou que no país existiam 2 I PPG-EF. Desses, 48\% possuíam programas dirigidos à formação de doutores. Apenas na última década houve a inclusão de sete novos cursos, sob a justificativa de que o desenvolvimento acadêmico e profissional da área seria resultante do aumento de massa crítica, promovido a partir da pós-graduação.

Entretanto, a formação de docentes críticos e criativos, que possam contribuir para a EF não depende apenas do número de PPG-EF, mas de sua qualidade. Os mesmos dados apontam que 48\% dos PPG-EF possuem conceito 3, o mesmo valor somando o número de programas com conceito 4 e 5 (divididos em igual proporção, 24\%). Atualmente, apenas o programa da Escola de Educação Física e Esporte da Universidade de São Paulo foi classificado com conceito $6^{2}$.

É evidente que atualmente se produz mais informação que há 40 anos, porém os critérios estabelecidos para avaliar os PPG - EF demonstram que ainda existem discrepâncias em relação à qualidade desses programas. Portanto, mais que incentivar a abertura de novos programas, é necessário consolidar os que já existem, criando condições para a formação crítica dos alunos. Isso implicaria na reforma da

2. O uso desses conceitos é controverso em função dos indicadores utilizados para atribuição de notas. No entanto, é o único disponível para classificar os programas de pós-graduação sticto sensu. Para maiores informações, consulte: http://www.capes.gov.br/avaliacao/avaliacao-da-pos-graduacao, Sacardo (2007), Lovisolo (2007). 
própria universidade, aproximando a comunidade acadêmica e a sociedade, conforme destaca Taffarel (2007): "não nos basta defender uma política científica para a área de Educação Física com ênfase na pós-graduação, [mas também devemos garantir maior integração entre] graduação/pós-graduação, ensino básico/superior e universidade/sociedade".

Nesse documento, Taffarel (2007) denuncia as diferenças regionais em relação a essa política de desenvolvimento dos PPG e de financiamento público, pois retrata que até o presente não existe nenhum programa de mestrado em EF no norte ou nordeste do país. Retrata ainda uma produção científica e tecnológica alienada, sobremodo porque é orientada pela lógica da produção capitalista de ciência.

Logo, a produção do conhecimento alienada considera a pesquisa e não o ser humano como um fim em si mesmo, além de não se envolver com questões relevantes para a sociedade e profissão. Por isso, o conhecimento deve assumir um caráter prático, de modo que funcione como uma ferramenta de compreensão e transformação científica e social, tal como Proust (apud FOUCAULT, 1979, p. 7I) destaca em seus textos: "tratem meus livros como óculos dirigidos para fora e se eles não lhes servem, consigam outros, encontrem vocês mesmos seu instrumento, que é forçosamente um instrumento de combate".

Todavia, a elaboração do saber é realizada, seja de forma explícita ou oculta, de acordo com interesses políticos e econômicos do capital. Quando esses interesses se sobrepõem à missão da universidade ${ }^{3}$, há a estruturação das "universidadesmercado", onde o importante é a produção quantitativa e a comercialização de informação e tecnologia. Para sustentar esse sistema, essas "universidades-mercado" reformulam o discurso ideológico que orienta sua produção tecno-científica, reorganizam o labor e o espaço e empregam a disciplina para garantir a produção de informação (FOUCAULT, 1979).

Portanto, inicialmente há uma apropriação do discurso ideológico, manipulando os veículos de comunicação e os modos de produção, orientando-os para atender aos interesses de uma elite econômica mundial. Num segundo momento, se apropria e ressignifica o trabalho, orientando-o a produção de uma riqueza estratégica, seja ela cultural, científica, tecnológica ou econômica. Daí a valorização do trabalho técnico dos estudantes (principalmente de iniciação científica e mestrado)

3. Especificamente no caso da Universidade de São Paulo, sua missão é "Promover a pesquisa e o progresso da ciência; transmitir pelo ensino conhecimentos que enriqueçam ou desenvolvam o espírito e que sejam úteis à vida; e formar especialistas em todos os ramos da cultura e em todas as profissões de base científica ou artística. 
que almejam uma cadeira docente. Paul Forman (apud TAFFAREL, 2007, p.49), um dos principais historiadores da física, nos alerta sobre assunto:

A ciência é cada vez mais 'uma empresa política e econômica'. Atualmente, a ciência é valorizada simplesmente como um componente da tecnologia, e esta não como um meio para fazer ciência. A tecnologia se transforma no propósito da ciência, estabelece seus objetivos e orienta sua atividade, não mais concebida como dotada de seus próprios fins ou objetivos intrínsecos, porque carente de uma concepção hierárquica de conhecimento: a ciência é incapaz de criar seus próprios fins, a tecnologia se converte no instrumento e objetivo indispensável da atividade científica.

Logo, a ciência perde seu caráter primordial para atender a interesses políticos e econômicos de uma classe que participa do controle de diversas instâncias sociais, incluindo a científica e, principalmente, tecnológica. A universidade desprovida de políticas públicas submete-se a esse mecanismo de controle sutil. ${ }^{4}$

Para propagar esse controle, torna o sujeito detentor de uma parcela de poder, garantido uma produção científica e tecnológica dirigida a interesses econômicos. Importante destacar que esse poder não funciona de modo repressivo e impositivo; sobremodo porque tais sistemas necessitam de políticas punitivas dispendiosas para sua manutenção. Inversamente, o poder se manifesta produzindo o prazer, o discurso, o saber e a recompensa econômica e pessoal. $\bigcirc$ exemplo seria o pesquisador que, diante do risco de não atender as exigências do poder, envereda pelo caminho da produção técnica para atender as necessidades burocráticas e ideológicas do sistema acadêmico.

Finalmente, são introduzidos os mecanismos de vigilância e registro para regular essa atividade tecno-científica. Alguns dos critérios de avaliação dos órgãos de fomento e regulamentação dos PPG para classificar instituições e docentes estão fundamentadas em tais políticas. Desde 1975, com a criação do GCE, houve o interesse em promover a Educação Física. Todavia, 35 anos depois desse projeto político, observa-se uma acentuação das desigualdades entre sul/sudeste e norte/ nordeste (TAFFAREL, 2007). Assim, o projeto de desenvolvimento nacional não foi dirigido a todas as regiões do país, o que nos leva a questionar quais seriam os interesses da concentração de capital financeiro e científico no sul e sudeste.

A suposta neutralidade dos indicadores que regulam e fomentam os programas de pós-graduação são selecionados a partir de um entendimento da realidade,

4. Apenas para exemplificar, Josué de Castro (200 I) questiona sobre a escassez bibliográfica de um tema de grande importância social, a fome. Segundo ele, não existe um investimento maciço para estudar fenômenos associados à miséria, orientando a pesquisa a questões que atendam aos interesses do capital. 
do esporte e da educação física. Questões como produção científica (SACARDO, 2007), publicação na língua pátria ou estrangeira (RODRIGUES, 2007), a diversidade de áreas que compõem a educação física (LOVISOLO, 2005) e a vocação das universidades (de pesquisa ou de ensino) são usualmente problemáticas desconsideradas quanto à seleção de critérios de avaliação. Entretanto, são as escolhas desses critérios que acentuam as desigualdades e dificultam o deslocamento de recursos para regiões fora do eixo sul-sudeste.

\section{PROPOSIÇÕES SOBRE A UNIVERSIDADE}

A apropriação do trabalho e do saber, associada aos mecanismos de vigilância e registro, converge para a elaboração do conceito que denominamos nesse ensaio de produção fordista do conhecimento, onde cada estudante seria responsável por uma parcela do trabalho acadêmico e por sua produção em massa, mas desconhecedor do trabalho total e de seu impacto social, similar ao proposto por Henry Ford (1863-1947).

Esse modelo de produção fordista permite um fluxo de publicações que atendem aos critérios estabelecidos pelos órgãos de fomento e avaliação, mas que por outro lado não promovem, necessariamente, a formação de massa crítica. A ciência não deve apenas estar comprometida com questões sociais, mas áreas de intervenção como a Educação Física deveriam produzir conhecimentos que contemplassem tais questões.

Segundo Severino (2006), a natureza dos PPG é produzir conhecimento decorrente da pesquisa, explicitando as exigências epistemológicas, metodológicas e técnicas do processo investigativo. Salienta ainda que a pós-graduação não se constitui como um processo de escolarização, de forma que sua principal finalidade é efetivamente criar um conhecimento original, que faça avançar a ciência na área.

Estima-se que anualmente gaste-se no Brasil cerca de $\mathrm{R} \$$ । .200,00 per capita para os alunos do ensino básico, ao passo que o investimento no ensino superior está em torno de $R \$ 12.000,00$ (SCHWARTZMAN, 2004). Além disso, há uma redução no número de estudantes por docente em função do grau de instrução. Isso implica que o docente universitário dedique-se menos à questão pedagógica e mais à pesquisa.

Apesar de representar uma pequena parcela da carga horária do docente universitário em instituições com tradição em pesquisa, a questão pedagógica é importante para não desperdiçar recursos e garantir a qualidade da produção do saber e da formação dos alunos nos PPG. 
Após a aprovação do decreto n 2306 promovido pelo GERES (Grupo Executivo para a Reformulação do Ensino Superior) em 19 de agosto de 1997, que resultou na distinção entre universidade de pesquisa e universidade de ensino (SAVIANI, 2006), a questão pedagógica tornou-se ainda mais importante, visto que serão as universidades de pesquisa que formarão docentes para as universidades de ensino.

Considerando que as instituições privadas abarcam $70 \%$ dos alunos de graduação (SCHWARTZMAN, 2004), e que os recursos destinados à pesquisa nessas instituições são escassos, é importante que esses mestres e doutores estejam preparados para atuar em diferentes níveis de pesquisa (teórica, conceitual e factual) e com embasamento pedagógico consolidado. Além disso, o número de universidades, especialmente privadas, tende a crescer diante das políticas de incentivo ao ensino superior e da ausência de tradição universitária no Brasil (SCHWARTZMAN, 2004). Por isso, será vital a proporcional expansão de PPG que proporcionem uma formação pedagógica, política e científicometodológica sólida.

A Educação Física se constitui como ciência produtiva, ou seja, seu objeto de investigação não é oriundo de fenômenos naturais, mas forjado a partir de necessidades sociais e políticas (BRESSAN, 1979). Sua justificativa como disciplina acadêmica está fundamentada na capacidade de intervir na sociedade. Portanto, a segmentação da Educação Física (incluiríamos o Esporte) em duas "culturas" (básica/ aplicada) e sua descaracterização para atender as necessidades das ciências básicas, conforme proposto por Tani (1999), poderá causar o extermínio da profissão, que por sua vez aniquilará a disciplina acadêmica (BRESSAN, 1979).

A finalidade da pós-graduação é qualificar seres humanos para docência e pesquisa. No entanto, os PPG-EF têm dirigido pouca atenção para a atividade pedagógica e ao conhecimento direcionado aos problemas profissionais da área. O desfecho será docentes produtivos, mas pouco criativos e despreocupados com o objeto de investigação.

Darcy Ribeiro (1975) prevê os riscos do modelo fordista nas universidades. Considerando que o desenvolvimento social e econômico de um país é proporcional ao desenvolvimento tecnológico e científico, é evidente a necessidade de políticas legítimas e investimentos no setor educacional. A criatividade e o exercício crítico (atividade qualitativa), associada à produção em larga escala num segundo momento (atividade quantitativa) seriam as responsáveis pela emancipação do país.

Algumas proposições discutidas nos encontros do CBCE (Colégio Brasileiro de Ciências do Esporte) contribuem para orientação do caminho que a Educação 
Física poderia seguir para desarticular essa produção fordista do conhecimento 5 . São elas:

- Inserção na construção de políticas públicas, defendendo direitos democráticos à Educação Física, esporte, lazer, saúde e qualidade de vida da população, implicando na questão da urbanização, saneamento básico, habitação, entre outros.

- Concepção de ciência, não apenas fundamentada no modelo estadunidense, mas como entidade que congregue as ciências sociais e humanas além da área médica.

- Articulação da pós-graduação com profissionais e estudantes de ensino básico e superior, criando ambiências para que os problemas profissionais sejam discutidos na academia, aproximando o conhecimento produzido da sociedade.

- Expansão da pós-graduação para todas as regiões do país, repensando os critérios que regulam e fomentam os programas nas instituições de ensino superior.

Todas essas questões parecem colocar a universidade como órgão estratégico para promover mudanças. Por isso, a necessidade e importância de repensar nosso sistema universitário e as políticas que o orientam.

\title{
O PAPEL ESTRATÉGICO DA UNIVERSIDADE
}

\begin{abstract}
Há duas imagens opostas da universidade latino-americana. Discursos acadêmicos carentes de sentido destacam a universidade como instituição dedicada a cultivar e a fazer florescer o espírito humano em suas formas mais criativas; desenvolver nos estudantes a consciência de sua dignidade humana, o zelo por sua liberdade espiritual, e pelos mais profundos sentimentos de tolerância, serenidade, justiça e equanimidade, juntamente com a felicidade espiritual, a alegria intelectual e a tranquilidade moral. [Na verdade, essas são] frases retóricas totalmente alheias à práxis, alienando a universidade de si mesma, [e exercendo] a função de ocultar a universidade real: impura, pelos componentes espúrios que o acadêmico tradicional prefere ignorar, apesar de conhecê-los muito bem; incômoda, pelos conteúdos inconformistas que ele gostaria de silenciar, e perigosa por estar cheia de descontentes dispostos a transfigurá-la". (RIBEIRO, 1975, p. 86).
\end{abstract}

5. Para maiores detalhes, consulte Taffarel (2007). 
Independente da vocação e infraestrutura das instituições, existe a necessidade de aprimoramento educacional e científico. Essa reforma organizacional não pode enveredar caminhos retóricos e teóricos ideais, mas deve estar pautada em indicadores objetivos associados a conclusões que desses indicadores podem ser extraídas.

Portanto, as instituições, os programas, o corpo administrativo, os funcionários, os docentes e discentes devem ser avaliados periodicamente. A avaliação é salutar para sociedade, empresas, estudantes e governo no que concerne o apoio e o investimento financeiro, o estabelecimento de políticas de desenvolvimento e a divulgação dos melhores programas de formação. Contudo, essa ferramenta não deve ser subvertida para simples controle político e intimidação (SCHWARTZMAN, 2004). Ao contrário, devem indicar caminhos para programas de qualidade internacional, avaliando de forma transparente.

Logo, a avaliação não deve ser empregada como um fim, na busca de melhores conceitos e maior aquisição de recursos junto aos órgãos de fomento, sacrificando a formação dos estudantes de pós-graduação e detrimento da produção fordista.

Para solucionar esses problemas estruturais das universidades seria necessária a elaboração de políticas de integração dos departamentos, centralizando recursos e organizando investigações numa estrutura transdisciplinar. Propostas direcionadas à transformação dessas universidades segmentadas para instituições integradas, que possuem excelência no ensino, pesquisa e extensão devem compor periodicamente a pauta reuniões acadêmicas, revertendo o conhecimento à sociedade, para emancipação científica e econômica do país (RIBEIRO, 1975).

Porém, usualmente nas grandes universidades os cursos são segmentados em departamentos "autárquicos" por seu isolamento e hostilidade uns com os outros (RIBEIRO, 1975). Isso resulta em atraso para a área, pois essas estruturas descompartimentalizadas concorrem por recursos financeiros e humanos, promovendo a competição e a rivalidade entre os docentes. Para agravar a situação, esses recursos financeiros (que são insuficientes para estruturar laboratórios competitivos internacionalmente), são mal empregados em investigações onerosas descomprometidas com os problemas sociais (TAFFAREL, 2007), distanciando cada vez mais a academia da profissão.

Atualmente na EF existem departamentos que investigam desde biologia molecular até sociologia do esporte. A estruturação de centros de assistência à comunidade poderiam funcionar como pólos de convergência entre esses diversos departamentos. Tais centros funcionariam dentro de um modelo transdisciplinar, seja para promoção da saúde, educação, cultura corporal, desempenho esportivo, entre outras (RIKLI, 2006; HATFIELD, 2008). 
Associado a isso, estruturar grupos de estudo e elaborar projetos preocupados em auxiliar as comissões esportivas e seus treinadores, os professores no âmbito escolar, e os profissionais que atuam na promoção da saúde e qualidade de vida também seriam possibilidades satisfatórias. Isso demandaria encontros fora dos muros da universidade entre profissionais e acadêmicos, reduzindo a aversão que existe entre ambos. Garantir um percentual de vagas em disciplinas para reciclagem dos egressos, avaliações mais equânimes e maior exigência nos cursos de graduação e pós-graduação também seriam pré-requisitos para transformação, desenvolvimento e consolidação da área. Um modelo similar tem sido evidenciado em outras áreas (SOARES, 2009), e tem apresentado resultados positivos. A proposta consiste num grupo de pesquisa que funciona como incubadora de micro e pequenas empresas, empregando o conhecimento produzido na universidade para a sociedade.

Para melhorar as políticas de avaliação e os caminhos científico-pedagógicos dos PPG o intelectual é peça fundamental. Ele será capaz de dirigir essas transformações em suas respectivas áreas, alertando os demais sobre o quadro político e dirigindo esforços de toda a comunidade para tais transformações.

Fundamentado numa filosofia da práxis, o intelectual "orgânico" conforme destaca Gramsci apud Semeraro (2006, p. 374) deve considerar "as dinâmicas sociais, políticas e econômicas" na construção de uma democracia popular, rompendo com a dinâmica fordista de produção de informaçãa. Sendo ao mesmo tempo pesquisador, crítico e revolucionário (SEMERARO, 2006), deve empregar a ciência e a tecnologia como instrumento de transformação e não de alienação social. Enfim, deve ser capaz de promover a reflexão e a interlocução com a sociedade, rompendo aos desígnios da produtividade, da competição e do mercado (SEMERARO, 2006).

\section{CONSIDERAÇÕES}

O objetivo do presente estudo foi discutir a orientação política dos PPG-EF e problematizar suas implicações para produção do conhecimento e a formação docente. A ênfase na produção factual fordista tem contribuído para distanciar o conhecimento produzido no PPG stricto sensu em EF da sociedade.

Portanto, instituir projetos de investigação e grupos de estudos preocupados com o desenvolvimento profissional, elaborando indicadores de avaliação além da publicação científica e articulando ensino, pesquisa, extensão, graduação, ensino básico e sociedade são essenciais para promover transformações.

Propostas como a criação de centros de pesquisa que atendam a comunidade 
(HATFIELD, 2008), a publicação em outros canais orientados ao crescimento do público leigo culto (GHIRALDELLI JR., 2006), a encubação de escolas e clubes, a assessoria de treinadores e atletas ou mesmo a avaliação do livro (CARVALHO et al., 2008) são exemplos de outros indicadores além do artigo científico que podem ser empregados para avaliar e aproximar a sociedade da universidade, modificando as políticas pedagógicas da instituição e alinhando-as com o desenvolvimento educacional e científico do país.

Finalmente, destituir os departamentos "autárquicos" dentro das universidades, centralizando recursos financeiros e humanos e orientando a pesquisa científica e a produção tecnológica para os problemas da área e da sociedade é a vereda para emancipação da dependência econômica e de um ensino, pesquisa e extensão de qualidade.

\section{The Acadennic Fordism in Physieal Edueation}

ABSTRACT: Despite the consolidation of stricto sensu postgraduate programs in Physical Education (PP-PE), critics have been noted. Among the principal, it is pointed out the technical formation and specialization on the initial periods of scientific formation, the distance between knowledge and society, the emphasis on the quantitative bibliographic production, guiding the aim of research for publication. This form of scientific production is entitled as academic fordism. Thus, the aim of this essay is discuss the orientation politic of the PP$P E$ and your implication to knowledge production and academic formation. The emphasis on bibliographic production and the devaluation of the PE likes area of intervention may implicate on the critical formation and result in mischaracterization of area.

KEYWORDS: Postgraduate studies; scientific policy; production of knowledge.

\section{El fordismo académico en la educación física}

RESUMEN: Pese a la consolidación de los estudios de postgrado en Educación Física (PPG-EF), las críticas han sido frecuentes. Entre aquellas que son centrales, están la formación técnica y la especialización en los tiempos iniciales de formación científica, la lejanía entre la producción de conocimiento y de la sociedad, y la valoración cuantitativa de la producción bibliográfica, cuando se pone los objetivos de investigación bajo la orientación para la publicación. Llamamos a este modo de producción científica de fordismo académico. El objetivo de este ensayo es discutir la orientación política de PPG-EF y refletir sobre sus implicaciones para la producción de conocimiento y para la formación académica. El énfasis en la producción bibliográfica y la desvalorización de la EF como un espacio de intervención puede poner en peligro la formación crítica y resultar en una descaracterización del área.

PALABRAS CLAVE: Postgrado; política científica; producción del conocimiento.

\section{REFERÊNCIAS}


BETTI, M.; CARVALHO, Y. M.; DAOLIO, J.; PIRES, G. L. A avaliação da Educação Física em debate: implicações para a subárea pedagógica e sociocultural. Revista Brasileira de PósGraduação, Brasília, v. I , n. 2, p. I83-194, nov. 2004.

BRESSAN, E. S. The profession is dead. Was it murder or suicide? Quest, Champaign, v. 31 , n. I, p. 77-82, fev. 1979.

CARDOSO, J. R.; BURIAN, Y.; LYRA, A. C. C.; MUHLEN, S. S. Uma nova pós-graduação em Engenharia: será está a solução? Jornal da USP: Publicação da Coordenadoria de Comunicação Social, São Paulo, p. 2, 16 fev. 2009.

CARVALHO, Y. M.; MANOEL, E. J.; NOVAES, B. C. A. C.; GUIRRO, R. R. J.; BRACHT, V. O livro na pós-graduação: uma metodologia para avaliação do livro. Revista Brasileira de Pós-Graduação, Brasília, v. 5, n. 10, p. 226-249, dez. 2008.

CASTRO, J. Geografia da fome: o dilema brasileiro: pão ou aço. 14. ed. Rio de Janeiro: Civilização Brasileira, 2001.

FOUCAULT, M. Microfísica do poder. Tradução Roberto Machado. 25. ed. Rio de Janeiro: Graal, 2008.

FREIRE, P. Pedagogia da autonomia: saberes necessários a prática educativa. 37. ed. São Paulo: Paz e Terra, 1996.

GHIRALDELLI JR., P. Treze teses sobre a pós-graduação no Brasil em Filosofia, Ciências Sociais e Educação. In: BIANCHETTI, L.; MACHADO, A. M. N. A bússola do escrever: desafios e estratégias na orientação e escrita de teses e dissertações. 2. ed. Florianópolis: Cortez - UFSC, 2006, p. 301-327.

HATFIELD, B. D. E Pluribus Unum - from DNA to social systems: understanding physical activity trough an integrated perspective. Quest, Champaign, v. 60, p. 154-177, fev. 2008.

KOKUBUN, E. Pós-graduação em Educação Física no Brasil: indicadores objetivos dos desafios e das perspectivas. Revista Brasileira de Ciências do Esporte, Campinas, v. 24, n. 2, p. 9-26, nov. 2003.

Sobre a pós-graduação em Educação Física. In: NETO, A. F. et al. Leituras da natureza científica do Colégio Brasileiro de Ciências do Esporte. Campinas: Autores Associados, 2005. p. 45-69. p. 7I-90.

LOVISOLO, H. R. "Levantando o sarrafo ou dando um tiro no pé": critérios de avaliação e qualis das pós-graduações em Educação Física. Revista Brasileira de Ciências do Esporte, Campinas, v. 29, n. I , p. 23-33, set. 2007.

MACHADO, A.; LOURENÇO, O.; SILVA, F. J. Facts, concepts, and theories: the shape of psychology's epistemic triangle. Behavior and Phylosophy, Beverly, v. 28, p. I-40, 2000. 
PARDO, E.; RIGO, L.C. Educação Física como ciência: para sair do século XIX. Revista Brasileira de Ciência do Esporte, Campinas, v. 22, n. I, p. 39-5I, set. 2000.

PEREIRA, B. As limitações do método científico: implicações para a educação física. Revista Paulista de Educação Física, São Paulo, v. 12, n. 2, p. 228-248, jul. 1998.

RIBEIRO, D. A universidade necessária. 3. ed. Rio de Janeiro: Paz e Terra, 1975.

RIKLI, R. Kinesiology: A "homeless" field: Addressing organization and leadership needs. Quest, Champaign, v. 88, p. 288-309, Agosto 2006.

RODRIGUES, L. O. C. Publicar mais, ou melhor? $\bigcirc$ tamanduá olímpico. Revista Brasileira de Ciências do Esporte, Campinas, v. 29, n. I, p. 35-48, setembro 2007.

SACARDO, M. S. Reflexões acerca da pós-graduação brasileira: o impacto dessa política na área da Educação Física. Revista Brasileira de Ciências do Esporte, Campinas, v. 29, n. I, p. 75-88, setembro 2007.

SAVIANI, D. A pós-graduação em educação no Brasil: pensando o problema da orientação. In: BIANCHETTI, L.; MACHADO, A. M. N. A bússola do escrever: desafios e estratégias na orientação e escrita de teses e dissertações. $2^{a}$ edição. Florianópolis: Cortez - UFSC, 2006, p. 135-163.

SCHAWARTZMAN, S. Educação: a nova geração de reformas. In: GIAMBIAGI, F; REIS, J. G.; URANI, A. Reformas no Brasil: balanço e agenda. Rio de Janeiro: Nova Fronteira, 2004, p. 48I-504.

SEMERARO, G. Intelectuais "orgânicos" em tempos de pós-modernidade. Caderno CEDES, Campinas, v. 26, n. 70, p. 373-39I, set. / dez. 2006.

SEVERINO, A. J. Pós-graduação e pesquisa: $O$ processo de produção e sistematização do conhecimento no campo educacional. In: BIANCHETTI, L.; MACHADO, A. M. N. A bússola do escrever: desafios e estratégias na orientação e escrita de teses e dissertações. 2. ed. Florianópolis: Cortez - UFSC, 2006, p. 67-87.

SILVA, R. V. S. As ciências do esporte no Brasil nos últimos vinte anos: Contribuição da pósgraduação estrito senso. Revista Brasileira de Ciências do Esporte, Florianópolis, p.54-64, set. 1998. Número especial.

C CBCE e a produção do conhecimento em Educação Física em perspectiva. In: NETO, A. F. et al. Leituras da natureza científica do Colégio Brasileiro de Ciências do Esporte. Campinas: Autores Associados, 2005. p. 45-69.

SOARES, O. O lugar da pesquisa em inovação. Jornal da USP: Publicação da Coordenadoria de Comunicação Social. São Paulo, p. 4, 23 março 2009.

TAFFAREL, C. Z. Política científica e produção do conhecimento na Educação Física/ciência do esporte: a conjuntura, as contradições e as possibilidades de superação. In: CARVALHO, 
Y. M.; LINHALES, M. A. Política científica e produção do conhecimento em Educação Física. Goiânia: Colégio Brasileiro de Ciências do Esporte, 2007. p. 17-7I.

TANI, G. Atividade de pesquisa na Escola de Educação Física e Esporte da Universidade de São Paulo: passado, presente e futuro. Revista Paulista de Educação Física, São Paulo, v. I 3 , p. 20-35, dez. 1999.

.Educação Física: por uma política de publicação visando à qualidade dos periódicos. Revista Brasileira de Ciências do Esporte, Campinas, v. 29, n. I, p. 9-22, set. 2007.

Recebido: 23 set. 2009

Aprovado: 10 mai. 2010

Endereço para correspondência:

Eduardo Rumenig Souza

Rua Frederico Grotte, 64, apto 58

Bairro: Jardim Vergueiro

São Paulo - SP

CEP: 058।8-270 